\title{
Refractory Paraganglioma
}

National Cancer Institute

\section{Source}

National Cancer Institute. Refractory Paraganglioma. NCI Thesaurus. Code C158401.

A paragang lioma that does not respond to treatment. 